\title{
Gender differences in the association of obesity-related measures with multi-morbidity among older adults in India: evidence from LASI, Wave-1
}

\author{
T. Muhammad ${ }^{1}$ (1), Bandita Boro², Manish Kumar ${ }^{1}$ and Shobhit Srivastava ${ }^{1^{*}}$ (])
}

\begin{abstract}
Background: Co-existence of multiple chronic diseases is increasingly becoming a norm among ageing population. The study aims to investigate the prevalence of multimorbidity and the association between anthropometric measures of obesity and multimorbidity among men and women aged 60 years and above in India.

Methods: The present study is based on the first wave of the Longitudinal Aging Study in India. The analytical sample size for the study was 28,050 older adults aged 60 years and above. Descriptive statistics and multivariable analysis using logistic regression models were conducted.

Results: Body Mass Index (BMI) based-obesity is more prevalent among older women than men (26.3\% vs. 17.6\%). Similarly, higher proportion of older women was at high-risk waist circumference (37.1\% vs $8.9 \%)$ and waist-hip ratio (78.5 vs 75.4\%) than men respectively. In Model-I, after controlling for several covariates, older adults with overweight/ obesity were 1.6 times more likely to have multi-morbidity than non-obese older adults (Adjusted OR=1.61; 95\% Cl: 1.48-1.74). Similarly, older adults with high-risk waist circumference [Adjusted OR: 1.66; 95\% Cl: 1.52-1.80] and waisthip ratio [Adjusted OR: 1.45; 95\% Cl: 1.33-1.59] also had higher odds of having multi-morbidity in reference to their counterparts. In model-3 it was found that females with high-risk waist-hip ratio had 14\% lower odds of multimorbidity than males with high-risk waist-hip ratio [Adjusted OR: 0.86; 95\%Cl: 0.78-0.94].

Conclusion: The findings of the study show significant gender difference in the prevalence of multimorbidity, men being at increased risk in the multivariate analysis which is uncommon in the existing epidemiological research. Interactive effect of male gender with anthropometric measures on multimorbidity reported in our study probably due to increased unhealthy behaviours among men requires further research.
\end{abstract}

Keywords: Obesity-related measure, Multimorbidity, Older adults, India

*Correspondence: shobhitsrivastava889@gmail.com

${ }^{1}$ International Institute for Population Sciences, Mumbai, Maharashtra 400088, India

Full list of author information is available at the end of the article

\section{Background}

According to the Global Burden of Disease 2015 study, higher body mass index (BMI) is one of the highest and increasing risk factor contributing to poor health conditions [1]. A study in 2013 showed that nearly one third of the world's population was either overweight or obese [2]. More than $50 \%$ of the individuals with obesity in the world were found in 10 countries and India accounted for 
$15 \%$ in 2013 [3]. A higher prevalence of malnutrition, as characterized by underweight and overweight has been reported among the ageing population in India [4]. The increase in the double burden of overweight and obesity is also leading to a rise in chronic conditions which is an emerging problem in Asian countries including India [5].

Multi-morbidity at older ages leads to low quality of life, higher mortality rates, low physical and mental health, cognitive decline and higher healthcare expenditure $[6,7]$. In a systematic analysis of the prevalence of multi-morbidity in high, low and middle-income countries, it was found that more than $50 \%$ of those older than 65 years had multi-morbidity and that females were affected more [8]. A couple of studies in developing countries also found that more than half of the older adults had three plus chronic conditions $[9,10]$. In India, multi-morbidity is highly prevalent among older adults $[11,12]$, and significant gender differences have been reported in prevalence of multi-morbidity and associated mortality $[12,13]$. The increase in BMI may increases the impairments in physical functioning at older ages and lead to a greater risk of developing multi-morbidity for older adults [14-17]. Previous studies revealed that prevention of overweight and obesity among older adults can help in reducing the burden of chronic diseases [18, 19]. Along with obesity, anthropometric measures such as waist circumference and waist-hip ratio also provide an indirect evaluation of body composition and are considered as associated factors of chronic diseases as they are directly linked to excess body fat [20-22]. However, studies on waist circumference and waist-hip ratio as risk factors of multi-morbidity are scarce in India.

Co-existence of multiple chronic diseases is increasingly becoming a norm among ageing population [23]. On the other hand, a recent study found that the prevalence of overweight and obesity among Indian adults aged 20-69 years will be tripled by 2040 , and the largest increase will be seen in the older adults [24]. Therefore, a significant gender gap can be seen in the prevalence of obesity and overweight and thus it can have differential effects on multi-morbidity in older men and women. Although a significant gender difference in the prevalence of multi-morbidity was shown in a recent study in India [25], a gender-specific analysis of the association of anthropometric measures of obesity and multi-morbidity may offer insight into the differential contribution of these factors to the burden of multimorbidity in older men and women and the potential for prevention of multimorbidity in older Indian adults. This study is aimed to explore the association of obesity-related anthropometric indices with multi-morbidity in adults aged 60 years and above and the interaction of gender in those associations. Based on the abovementioned review of existing studies, a conceptual framework has been developed and summarized in Fig. 1.

\section{Methods \\ Data}

The present study is based on the first wave of the Longitudinal Aging Study in India (LASI) conducted during 2017-18 [26]. The LASI is a nationally representative longitudinal survey of middle-and older-aged adults in India (i.e., aged 45 years or older) and their spouses who reside in the same households, irrespective of age. The LASI survey provides rich information on demographics, morbidity, health behaviour factors, and physical health of the aging population in India. The major aim of the survey was to measure health and its determinants and consequences over the later stages of life. The survey adopted a multistage stratified area probability cluster sampling design. It is a nationally representative survey of 72,250 individuals aged 45 and above across all states and union territories of India. The LASI is envisioned to be conducted every two years for the next 25 years [26]. The number of targeted primary sampling units (PSUs) in a state was chosen proportionally to each sub-state area in the first step with the selection of PSUs (sub-districts or Tehsils/Talukas) (level 1 stratification). Thus, the PSUs were chosen using Probability Proportional to Size (PPS) sampling in each area, with the number of households in each PSU serving as the size measure. All PSUs (sub-districts) within each of these areas were specifically stratified using one or more of the following stratifying variables: 1) the total number of households in a subdistrict, 2) the level of female literacy, 3) the proportion of Scheduled caste and Scheduled tribe population, and 4) the proportion of males employed in non-agricultural activities. The second stage entailed selecting a predetermined number of secondary sampling units (SSUs) from the selected PSUs, which are villages in rural regions and wards in urban areas. The third step in rural regions entailed selecting a set number of homes (HHs) (i.e. 32) from each designated village or village segment (for villages with more than $500 \mathrm{HHs}$ ). In metropolitan regions, the fourth round of selection entailed selecting a set number of $\mathrm{HHs}$ (35 in this case) from each census enumeration block (CEB). The interviews were conducted using computer-assisted personal interview (CAPI).

The LASI survey is conceptually comparable to the United States Health and Retirement Study (HRS) and other HRS-type surveys in various countries, including China (China Health and Retirement Longitudinal Survey) and England (English Longitudinal Study of Ageing). Along with its uniqueness of comparability with studies in other countries, LASI also considered features unique to India, including its institutional and 


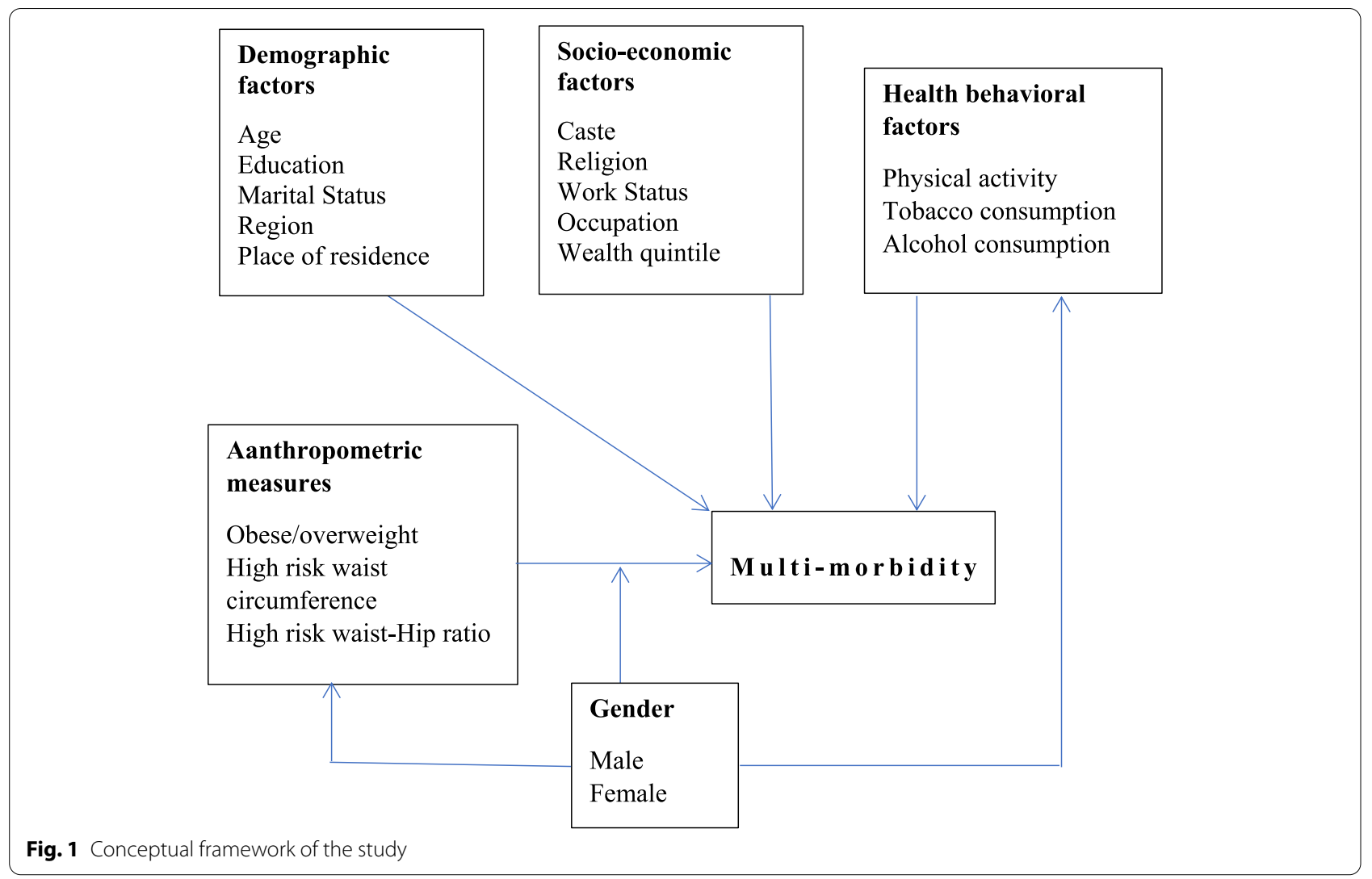

cultural characteristics. LASI is conducted through a partnership of the International Institute of Population Sciences (IIPS), Harvard University, and the RAND Corporation [26]. Additionally the study was funded by National Program for Health Care of Elderly, Ministry of Health and Family Welfare, Government of India, National Institute on Aging National Institutes of Health, USA and United Nations Population Fund, India [26]. Since we are interested in exploring the determinants of multi-morbidity among the older adults, we restrict our attention to the subsample of the Indian older adults and limit our sample to respondents aged 60 or above. All methods were performed in accordance with the relevant guidelines and regulations. The anthropometric measures were assessed by trained health investigators during the survey. The sample size of the present study was 31,464 respondents aged 60 years or older (male: 15,098 and female: $16,366)$ [26]. In case of obesity related measures, older respondents who gave consent were only considered; therefore, leading to the effective sample size for the present study to 28,050 older adults (male: 13,509 and females: 14,541). All methods were performed in accordance with the relevant guidelines and regulations and the data were fully anonymized in the study.

\section{Variable description}

Outcome description

Multi-morbidity refers to the presence of two or more chronic diseases [25, 27-30] which include hypertension, chronic heart diseases, stroke, any chronic lung disease, diabetes, cancer or malignant tumour, any bone/joint disease, any neurological/psychiatric disease or high cholesterol. The variable was categorized to binary i.e., multimorbidity (no/yes) [31-35]. The chronic diseases were assessed using the question "has any health professional ever diagnosed you with the following chronic conditions or diseases?". The responses were available as yes and no; therefore, considered as self-reported conditions [36].

\section{Explanatory variables}

The variables controlled for the present study were taken into consideration after extensive literature review. Body Mass Index (BMI) was calculated as weight in kilograms divided by height in meters squared. The respondents having body mass index of 25 and above were categorized as obese/overweight [26]. Overweight/obesity was categorized as no and yes. High risk waist circumference was categorized as no and yes. Male and female who have waist circumferences of more than $102 \mathrm{~cm}$ and $88 \mathrm{~cm}$ respectively were considered as having high risk waist 
circumference [37]. High risk waist-hip ratio was categorized as no and yes [37]. Male and female who have waist-hip ratio of $\geq 0.90$ and $0.85 \mathrm{~cm}$ respectively were considered as having high risk waist-hip ratio [37].

Age was categorized as young old (60-69 years), oldold (70-79 years) and oldest-old ( $80+$ years). Education was categorized as no education/primary schooling not completed, primary completed, secondary completed and higher and above. Marital status was categorized as currently married, widowed and others (separated/ never married/divorced). Working status was categorized as working, not working/retired, and never worked. Tobacco and alcohol consumption was assessed through the questions 'have you ever smoked tobacco or used tobacco products?, 'And have you ever consumed alcoholic beverages such beer, wine, liquor, etc.?' It was coded as no and yes [38]. Physical activity status was categorized as frequent (every day), rare (more than once a week, once a week, one to three times in a month) and never. The question through which physical activity was assessed was "How often do you take part in sports or vigorous activities, such as running or jogging, swimming, going to a health centre or gym, cycling, or digging with a spade or shovel, heavy lifting, chopping, farm work, fast bicycling, cycling with loads"? [26]

The monthly per capita consumption expenditure (MPCE) quintile was measured using the information related to household-level consumption of food and non-food items. The reference periods for food expenditure were seven days and for non-food expenditure were 30 days and 365 days. These expenditures have been standardized to the 30-day reference period. The MPCE is computed and used as the summary measure of consumption [26] and divided into five quintiles, i.e., from poorest to richest. Religion was categorized as Hindu, Muslim, Christian and Others. Caste was categorized as Scheduled Tribe, Scheduled Caste, Other Backward Class and others. The Scheduled Caste include a group of population which is socially segregated and financially/ economically by their low status as per Hindu caste hierarchy [39]. The Scheduled Castes (SCs) and Scheduled Tribes (STs) are among the most disadvantaged socioeconomic groups in India [39]. The $\mathrm{OBC}$ is a group of intermediate categories which are identified as "socioeconomically and educationally backward" [39]. The "other" caste category is identified as having higher social status [39]. Place of residence was categorized as rural and urban. Region was categorized as North, Central, East, Northeast, West and South.

\section{Statistical analysis}

Descriptive statistics along with bivariate analysis was presented in the paper. The analysis was stratified by gender. To signify the association between gender differentials, proportion test [40] was used. Additionally, multivariable regression analysis [41] was used to establish the association between outcome variable (multi-morbidity) and other explanatory variables.

The binary logistic regression model is usually put into a more compact form as follows:

$$
\operatorname{Logit}[\mathrm{P}(\mathrm{Y}=1)]=\beta_{0}+\beta * X
$$

The parameter $\beta_{0}$ estimates the log odds of the multimorbidity for the reference group, while $\beta$ estimates the maximum likelihood, the differential $\log$ odds of the multi-morbidity associated with set of predictors $\mathrm{X}$, as compared to the reference group. Variance inflation factor was estimated to measure the multi-collinearity among the variable used and it was found that there was no multi-collinearity found in the variable used [42].

The multivariable analysis had four models to explain the adjusted estimates. Model-1 provides the adjusted estimates for the control variables. Model-2, model- 3 and model-4 provide the interaction effects $[43,44]$ for overweight/obesity indicators and gender with multi-morbidity among older adults.

\section{Results}

Table 1 presents the socio-demographic and economic profile of male and female older adults. BMI-based obesity was more prevalent among older women than men ( $26.3 \%$ vs. $17.6 \%)$. Similarly, a higher proportion of older women were at high-risk waist circumference and waisthip ratio than men. A higher proportion of older women were uneducated than older men $(81.4 \%$ vs. $53.1 \%)$. According to marital status, around two-fifth of older men $(81 \%)$ were currently married; however, this proportion was only $44 \%$ for older women. Nearly more than half of the older women (54\%) were widowed. Around $43 \%$ of the older men and $19 \%$ of women were working at the time of the survey.

Table 2 presents the results from the bivariate analysis of the prevalence of multi-morbidity among older adults stratified by gender. The prevalence of multimorbidity was higher in older women with overweight/ obesity than in men (44.9\% vs. $38.8 \%)$, with a difference of around $6 \%$. A similar pattern was observed for the high-risk waist-hip ratio measure. On the contrary, the prevalence of multi-morbidity was nearly $5 \%$ higher among the older men who were at a high risk of waist circumference than women. Irrespective of the age-groups, educational status, and marital status, the multi-morbidity prevalence was a bit steeper for women than men. We found that the prevalence of multi-morbidity increases with an increase in the age and the educational level for both men and women 
Table 1 Socio-demographic and economic profile of older adults $(n=31,464)$, LASI, 2017-18

\begin{tabular}{|c|c|c|c|c|}
\hline \multirow[t]{2}{*}{ Background characteristics } & \multicolumn{2}{|l|}{ Male } & \multicolumn{2}{|l|}{ Female } \\
\hline & Sample & $\%$ & Sample & $\%$ \\
\hline \multicolumn{5}{|l|}{ Obese/overweight $^{\mathrm{a}}$} \\
\hline No & 11,132 & 82.4 & 10,719 & 73.7 \\
\hline Yes & 2,377 & 17.6 & 3,822 & 26.3 \\
\hline \multicolumn{5}{|l|}{ High risk waist circumference ${ }^{a}$} \\
\hline No & 12,303 & 91.1 & 9,155 & 63.0 \\
\hline Yes & 1,205 & 8.9 & 5,387 & 37.1 \\
\hline \multicolumn{5}{|l|}{ High risk waist-Hip ratio ${ }^{a}$} \\
\hline No & 3,318 & 24.6 & 3,146 & 21.6 \\
\hline Yes & 10,184 & 75.4 & 11,402 & 78.4 \\
\hline \multicolumn{5}{|l|}{ Age } \\
\hline Young-old & 8,730 & 57.8 & 9,678 & 59.1 \\
\hline Old-old & 4,702 & 31.1 & 4,803 & 29.4 \\
\hline Oldest-old & 1,666 & 11.0 & 1,886 & 11.5 \\
\hline \multicolumn{5}{|l|}{ Education } \\
\hline $\begin{array}{l}\text { No education/primary not com- } \\
\text { pleted }\end{array}$ & 8,018 & 53.1 & 13,314 & 81.4 \\
\hline Primary completed & 2,235 & 14.8 & 1,297 & 7.9 \\
\hline Secondary completed & 3,096 & 20.5 & 1,297 & 7.9 \\
\hline Higher and above & 1,748 & 11.6 & 458 & 2.8 \\
\hline \multicolumn{5}{|l|}{ Marital status } \\
\hline Currently married & 12,242 & 81.1 & 7,211 & 44.1 \\
\hline Widowed & 2,489 & 16.5 & 8,837 & 54.0 \\
\hline Others & 366 & 2.4 & 318 & 2.0 \\
\hline \multicolumn{5}{|l|}{ Work status } \\
\hline Working & 6,613 & 43.8 & 3,108 & 19.0 \\
\hline Not working/Retired & 7,907 & 52.4 & 5,593 & 34.2 \\
\hline Never worked & 578 & 3.8 & 7,665 & 46.8 \\
\hline \multicolumn{5}{|l|}{ MPCE quintile } \\
\hline Poorest & 3,145 & 20.8 & 3,681 & 22.5 \\
\hline Poorer & 3,219 & 21.3 & 3,611 & 22.1 \\
\hline Middle & 3,262 & 21.6 & 3,331 & 20.4 \\
\hline Richer & 2,902 & 19.2 & 3,136 & 19.2 \\
\hline Richest & 2,570 & 17.0 & 2,607 & 15.9 \\
\hline \multicolumn{5}{|l|}{ Religion } \\
\hline Hindu & 12,386 & 82.0 & 13,484 & 82.4 \\
\hline Muslim & 1,769 & 11.7 & 1,781 & 10.9 \\
\hline Christian & 388 & 2.6 & 511 & 3.1 \\
\hline Others & 555 & 3.7 & 590 & 3.6 \\
\hline \multicolumn{5}{|l|}{ Caste } \\
\hline Scheduled Caste & 2,836 & 18.8 & 3,113 & 19.0 \\
\hline Scheduled Tribe & 1,166 & 7.7 & 1,389 & 8.5 \\
\hline Other Backward Class & 6,925 & 45.9 & 7,308 & 44.7 \\
\hline Others & 4,172 & 27.6 & 4,556 & 27.8 \\
\hline \multicolumn{5}{|l|}{ Place of residence } \\
\hline Rural & 10,879 & 72.1 & 11,322 & 69.2 \\
\hline Urban & 4,219 & 28.0 & 5,044 & 30.8 \\
\hline \multicolumn{5}{|l|}{ Region } \\
\hline North & 1,863 & 12.3 & 2,096 & 12.8 \\
\hline
\end{tabular}

Table 1 (continued)

\begin{tabular}{llllllr}
\hline Background characteristics & \multicolumn{2}{l}{ Male } & & \multicolumn{2}{l}{ Female } \\
\cline { 2 - 3 } & Sample & $\%$ & & Sample & $\%$ \\
\hline Central & 3,395 & 22.5 & 3,202 & 19.6 \\
East & 3,713 & 24.6 & 3,729 & 22.8 \\
Northeast & 437 & 2.9 & 497 & 3.0 \\
West & 2,457 & 16.3 & 2,941 & 18.0 \\
South & 3,233 & 21.4 & 3,900 & 23.8 \\
Total & 15,098 & 100.0 & & 16,366 & 100.0
\end{tabular}

a The sample may differ due to missing observations; MPCE Monthly per capita consumption expenditure

older adults. According to marital status, multi-morbidity was highly prevalent among female widows compared to male widows.

Table 3 presents the regression estimates of multi-morbidity according to different background characteristics among older adults in India. In model-1, after controlling for other covariates, older adults with obesity/overweight were 1.6 times more likely to be multi-morbid than older adults with no obesity (AOR $=1.61 ; 95 \% \mathrm{CI}$ : 1.48-1.74). Similarly, older adults with high risk waist circumference [AOR: 1.66; 95\%CI: 1.52-1.80] and waist-hip ratio [AOR: 1.45; 95\%CI: $1.33-1.59$ ] also had higher odds of being multi-morbid in reference to their counterparts. The older adults in the age-group 70-79 years had $26 \%$ higher odds of having multi-morbidity than the older adults in the age-group $60-69$ years $(\mathrm{AOR}=1.26$; $95 \% \mathrm{CI}$ : $1.17-1.34)$. Older women had $14 \%$ lower odds of being multi-morbid than older men (AOR $=0.86$; 95\%CI: 0.79 0.94). The increase in the level of education was associated with higher likelihood of multi-morbidity among the elderly. Currently unmarried older adults had lower odds of having multi-morbidity than the currently married older adults (AOR $=0.81$; 95\%CI: $0.67-0.99)$. The physically inactive older adults had 33\% higher odds of having multi-morbidity than frequently physically active older adults (AOR $=1.33 ; 95 \% \mathrm{CI}$ : 1.21-1.46). According to MPCE quintile, older people from higher MPCE quintile had greater odds of multi-morbidity among older adults. The respondents from urban areas had $43 \%$ higher odds of being multi-morbid than their rural counterparts $(\mathrm{AOR}=1.43 ; 95 \% \mathrm{CI}: 1.34-1.53)$. The participants who belonged to the western, eastern, and southern regions had higher odds of having multi-morbidity than those of the northern region. Model-2, model- 3 and model- 4 represent the interaction effects. In model-3 it was found that females with high risk waist-hip ratio had $14 \%$ significantly lower likelihood to be multi-morbid than males with high risk waist-hip ratio [AOR: 0.86 ; $95 \% \mathrm{CI}$ : $0.78-0.94]$. 
Table 2 Prevalence of multimorbidity among older adults stratified by gender, LASI, 2017-18, ( $n=28,050)$

\begin{tabular}{|c|c|c|c|c|}
\hline \multirow[t]{2}{*}{ Background characteristics } & \multirow{2}{*}{$\begin{array}{l}\text { Male } \\
\%\end{array}$} & \multirow{2}{*}{$\begin{array}{l}\text { Female } \\
\%\end{array}$} & \multirow[t]{2}{*}{ Difference } & \multirow[t]{2}{*}{$p$-value } \\
\hline & & & & \\
\hline \multicolumn{5}{|l|}{ Obese/overweight } \\
\hline No & 18.3 & 18.5 & -0.1 & 0.490 \\
\hline Yes & 38.8 & 44.9 & -6.1 & 0.001 \\
\hline \multicolumn{5}{|l|}{ High risk waist circumference } \\
\hline No & 19.6 & 16.1 & 3.4 & 0.001 \\
\hline Yes & 46.3 & 41.2 & 5.1 & 0.030 \\
\hline \multicolumn{5}{|l|}{ High risk waist-Hip ratio } \\
\hline No & 14.7 & 24.3 & -9.6 & 0.002 \\
\hline Yes & 24.3 & 27.4 & -3.2 & 0.001 \\
\hline \multicolumn{5}{|l|}{ Age } \\
\hline Young-old & 21.6 & 23.8 & -2.3 & 0.001 \\
\hline Old-old & 23.0 & 28.6 & -5.6 & 0.007 \\
\hline Oldest-old & 23.2 & 25.7 & -2.4 & 0.695 \\
\hline \multicolumn{5}{|l|}{ Education } \\
\hline No education/primary not completed & 17.1 & 21.3 & -4.2 & 0.001 \\
\hline Primary completed & 25.4 & 38.1 & -12.7 & 0.001 \\
\hline Secondary completed & 25.9 & 51.5 & -25.6 & 0.001 \\
\hline Higher and above & 34.8 & 36.8 & -2.0 & 0.008 \\
\hline \multicolumn{5}{|l|}{ Marital status } \\
\hline Currently married & 22.9 & 23.5 & -0.6 & 0.093 \\
\hline Widowed & 19.7 & 27.2 & -7.5 & 0.001 \\
\hline Others & 16.7 & 21.4 & -4.7 & 0.174 \\
\hline \multicolumn{5}{|l|}{ Work status } \\
\hline Working & 14.4 & 12.0 & 2.4 & 0.004 \\
\hline Not working/Retired & 28.6 & 24.7 & 3.9 & 0.001 \\
\hline Never worked & 23.9 & 31.5 & -7.6 & 0.001 \\
\hline \multicolumn{5}{|l|}{ Tobacco consumption } \\
\hline No & 26.8 & 26.7 & 0.1 & 0.906 \\
\hline Yes & 19.0 & 21.1 & -2.1 & 0.148 \\
\hline \multicolumn{5}{|l|}{ Alcohol consumption } \\
\hline No & 22.8 & 25.8 & -2.9 & 0.001 \\
\hline Yes & 20.5 & 13.2 & 7.3 & 0.001 \\
\hline \multicolumn{5}{|l|}{ Physical activity } \\
\hline Frequent & 16.4 & 18.0 & -1.6 & 0.208 \\
\hline Rare & 16.8 & 14.5 & 2.4 & 0.581 \\
\hline Never & 26.0 & 28.0 & -2.1 & 0.038 \\
\hline \multicolumn{5}{|l|}{ MPCE quintile } \\
\hline Poorest & 17.1 & 16.2 & 0.9 & 0.037 \\
\hline Poorer & 19.4 & 21.0 & -1.6 & 0.028 \\
\hline Middle & 19.3 & 25.0 & -5.7 & 0.001 \\
\hline Richer & 24.5 & 31.0 & -6.5 & 0.001 \\
\hline Richest & 33.1 & 38.6 & -5.5 & 0.181 \\
\hline \multicolumn{5}{|l|}{ Religion } \\
\hline Hindu & 21.7 & 24.5 & -2.8 & 0.001 \\
\hline Muslim & 22.7 & 29.2 & -6.5 & 0.001 \\
\hline Christian & 29.3 & 32.6 & -3.4 & 0.184 \\
\hline Others & 25.8 & 29.2 & -3.3 & 0.020 \\
\hline
\end{tabular}


Table 2 (continued)

\begin{tabular}{|c|c|c|c|c|}
\hline \multirow[t]{2}{*}{ Background characteristics } & \multirow{2}{*}{$\begin{array}{l}\text { Male } \\
\%\end{array}$} & Female & \multirow[t]{2}{*}{ Difference } & \multirow[t]{2}{*}{$p$-value } \\
\hline & & $\%$ & & \\
\hline \multicolumn{5}{|l|}{ Caste } \\
\hline Scheduled Caste & 18.6 & 20.4 & -1.8 & 0.367 \\
\hline Scheduled Tribe & 13.7 & 9.0 & 4.7 & 0.695 \\
\hline Other Backward Class & 22.2 & 27.4 & -5.1 & 0.001 \\
\hline Others & 26.9 & 30.8 & -3.9 & 0.001 \\
\hline \multicolumn{5}{|l|}{ Place of residence } \\
\hline Rural & 18.2 & 19.9 & -1.7 & 0.023 \\
\hline Urban & 32.5 & 37.8 & -5.3 & 0.001 \\
\hline \multicolumn{5}{|l|}{ Region } \\
\hline North & 23.3 & 25.3 & -2.1 & 0.014 \\
\hline Central & 13.1 & 13.8 & -0.7 & 0.878 \\
\hline East & 21.1 & 24.7 & -3.7 & 0.003 \\
\hline Northeast & 18.0 & 14.3 & 3.7 & 0.012 \\
\hline West & 27.9 & 27.6 & 0.3 & 0.058 \\
\hline South & 28.6 & 35.5 & -6.9 & 0.001 \\
\hline Total & 22.2 & 25.4 & -3.3 & 0.001 \\
\hline
\end{tabular}

Difference: Male-Female; MPCE Monthly per capita consumption expenditure

\section{Discussion}

The present study based on large country-representative survey information of older Indian adults aged 60 years and above, has shown the associations between several anthropometric measures and multi-morbidity in older ages with a special focus on gender difference in such associations. Although bivariate analyses in the current study showed female disadvantage in the prevalence of multi-morbidity, higher likelihood of multi-morbidity among older men than women in the multivariate analysis after adjusting for potential confounders was contrary to earlier studies in developed as well as developing countries that have revealed greater odds of multi-morbidity among older women, relating to their longer life expectancy and poor health status compared to older men [33, 45-48]. Since there is a dearth of studies due to lack of availability of large-scale data on multi-morbidity in low and middle income countries, the present study adds to the scientific evidence in geriatric research.

Older adults who were measured as obese in the study population, consistent with a couple of previous studies, were $61 \%$ more likely to report having multi-morbidity than older adults with no obesity [14, 22, 47]. Similarly, other two measures of obesity in our study, waist circumference and waist-to-hip ratio which are seldom studied in Indian context were also significantly associated with a higher prevalence of multi-morbidity among both older men and women, indicating that obesity is an important risk factor for morbidity in older ages. Other population-based studies conducted in low and middle income countries also found relationships between multimorbidity and measures of waist circumference and waist-to-hip ratio in older ages [22, 49]. The finding is in agreement with a recent study in India that found that adults aged 45 and above with obesity and high-risk waist circumference or waist-hip ratio were more likely to develop cardiovascular diseases than their counterparts [50], and another study reporting that a higher BMI among general population is associated with a greater prevalence of chronic diseases [51].

The current analysis shows that oldest age group is at reduced risk for multi-morbidity and is consistent with earlier studies [52, 53]. This might be an effect of survival bias in this cross-sectional analysis with increasing number of chronic diseases seems to be associated with mortality [52]. Similarly, it has been revealed that older age is associated with less accurate self-reporting of diseases [54], which may also explain the lower odds of multi-morbidity in oldest age group in our study. Considering the socioeconomic associations of multi-morbidity, the current results are in parallel with studies that have shown a different pattern in developing countries compared to developed ones with a greater prevalence among people with higher socioeconomic circumstances [5557]. The study found higher prevalence of multi-morbidity among individuals with higher levels of education, belonging to households with higher wealth quintiles and non-SC/STs. This also supports the positive relationship between wealth and health gradient in low and middle income countries shown by higher multi-morbidity 
Table 3 Logistic regression estimates for multimorbidity among older adults, LASI, 2017-18, ( $n=28,050)$

\begin{tabular}{|c|c|c|c|c|}
\hline \multirow[t]{2}{*}{ Background characteristics } & Model-1 & Model-2 & Model-3 & Model-4 \\
\hline & AOR $95 \% \mathrm{Cl}$ & AOR $95 \% \mathrm{Cl}$ & AOR $95 \% \mathrm{Cl}$ & AOR $95 \% \mathrm{Cl}$ \\
\hline \multicolumn{5}{|l|}{ Obese/overweight } \\
\hline No & Ref & & Ref & Ref \\
\hline Yes & $1.61 *(1.48-1.74)$ & & $1.62^{*}(1.50-1.76)$ & $1.60 *(1.48-1.74)$ \\
\hline \multicolumn{5}{|l|}{ High risk waist circumference } \\
\hline No & Ref & Ref & & Ref \\
\hline Yes & $1.66^{*}(1.52-1.8)$ & $1.64^{*}(1.5-1.79)$ & & $1.66^{*}(1.52-1.81)$ \\
\hline \multicolumn{5}{|l|}{ High risk waist-Hip ratio } \\
\hline No & Ref & Ref & Ref & \\
\hline Yes & $1.45^{*}(1.33-1.59)$ & $1.46^{*}(1.34-1.6)$ & $1.45^{*}(1.33-1.58)$ & \\
\hline \multicolumn{5}{|l|}{ Age } \\
\hline Young-old & Ref & Ref & Ref & Ref \\
\hline Old-old & $1.26^{*}(1.17-1.34)$ & $1.26^{*}(1.17-1.34)$ & $1.26^{*}(1.17-1.35)$ & $1.26^{*}(1.17-1.34)$ \\
\hline Oldest-old & $1.10(0.99-1.22)$ & $1.10(0.99-1.22)$ & $1.10(0.99-1.22)$ & $1.10(0.99-1.22)$ \\
\hline \multicolumn{5}{|l|}{ Gender } \\
\hline Male & Ref & & & \\
\hline Female & $0.86^{*}(0.79-0.94)$ & & & \\
\hline \multicolumn{5}{|l|}{ Education } \\
\hline No education/primary not completed & Ref & Ref & Ref & Ref \\
\hline Primary completed & $1.27^{*}(1.16-1.40)$ & $1.27^{*}(1.16-1.39)$ & $1.27^{*}(1.16-1.39)$ & $1.27^{*}(1.16-1.4)$ \\
\hline Secondary completed & $1.29^{*}(1.18-1.41)$ & $1.29^{*}(1.18-1.41)$ & $1.29^{*}(1.18-1.41)$ & $1.29 *(1.18-1.41)$ \\
\hline Higher and above & $1.24^{*}(1.10-1.39)$ & $1.24^{*}(1.10-1.4)$ & $1.25^{*}(1.11-1.4)$ & $1.24^{*}(1.10-1.39)$ \\
\hline \multicolumn{5}{|l|}{ Marital status } \\
\hline Currently married & Ref & Ref & Ref & Ref \\
\hline Widowed & $0.97(0.90-1.04)$ & $0.97(0.90-1.04)$ & $0.97(0.9-1.04)$ & $0.97(0.90-1.04)$ \\
\hline Others & $0.81 *(0.67-0.99)$ & $0.81 *(0.67-0.99)$ & $0.81^{*}(0.67-0.98)$ & $0.81 *(0.67-0.99)$ \\
\hline \multicolumn{5}{|l|}{ Work status } \\
\hline Working & Ref & Ref & Ref & Ref \\
\hline Not working/Retired & $1.79 *(1.64-1.94)$ & $1.79^{*}(1.64-1.94)$ & $1.79^{*}(1.64-1.94)$ & $1.79 *(1.64-1.94)$ \\
\hline Never worked & $1.77^{*}(1.60-1.96)$ & $1.76^{*}(1.59-1.95)$ & $1.76^{*}(1.59-1.95)$ & $1.77^{*}(1.60-1.96)$ \\
\hline \multicolumn{5}{|l|}{ Tobacco consumption } \\
\hline No & Ref & Ref & Ref & Ref \\
\hline Yes & $1.01(0.94-1.09)$ & $1.01(0.94-1.08)$ & $1.01(0.94-1.08)$ & $1.01(0.94-1.09)$ \\
\hline \multicolumn{5}{|l|}{ Alcohol consumption } \\
\hline No & Ref & Ref & Ref & Ref \\
\hline Yes & $1.04(0.95-1.14)$ & $1.04(0.95-1.14)$ & $1.04(0.95-1.14)$ & $1.04(0.95-1.14)$ \\
\hline \multicolumn{5}{|l|}{ Physical activity } \\
\hline Frequent & Ref & Ref & Ref & Ref \\
\hline Rare & $1.03(0.91-1.16)$ & $1.03(0.91-1.16)$ & $1.03(0.91-1.16)$ & $1.03(0.91-1.16)$ \\
\hline Never & $1.33^{*}(1.21-1.46)$ & $1.33^{*}(1.21-1.46)$ & $1.33^{*}(1.21-1.46)$ & $1.33^{*}(1.21-1.46)$ \\
\hline \multicolumn{5}{|l|}{ MPCE quintile } \\
\hline Poorest & Ref & Ref & Ref & Ref \\
\hline Poorer & $1.23^{*}(1.11-1.36)$ & $1.23^{*}(1.11-1.36)$ & $1.23 *(1.11-1.36)$ & $1.23^{*}(1.11-1.36)$ \\
\hline Middle & $1.39 *(1.26-1.53)$ & $1.39^{*}(1.26-1.53)$ & $1.38^{*}(1.25-1.53)$ & $1.39 *(1.26-1.53)$ \\
\hline Richer & $1.60 *(1.45-1.77)$ & $1.60^{*}(1.45-1.77)$ & $1.60 *(1.44-1.76)$ & $1.60 *(1.45-1.77)$ \\
\hline Richest & $1.98^{*}(1.79-2.19)$ & $1.98^{*}(1.79-2.19)$ & $1.98^{*}(1.79-2.19)$ & $1.98^{*}(1.79-2.19)$ \\
\hline \multicolumn{5}{|l|}{ Religion } \\
\hline Hindu & Ref & Ref & Ref & Ref \\
\hline Muslim & $1.32 *(1.21-1.45)$ & $1.33^{*}(1.21-1.45)$ & $1.32^{*}(1.21-1.45)$ & $1.32 *(1.21-1.45)$ \\
\hline
\end{tabular}


Table 3 (continued)

\begin{tabular}{|c|c|c|c|c|}
\hline Background characteristics & $\begin{array}{l}\text { Model-1 } \\
\text { AOR 95\% CI }\end{array}$ & $\begin{array}{l}\text { Model-2 } \\
\text { AOR } 95 \% \mathrm{CI}\end{array}$ & $\begin{array}{l}\text { Model-3 } \\
\text { AOR } 95 \% \mathrm{Cl}\end{array}$ & $\begin{array}{l}\text { Model-4 } \\
\text { AOR } 95 \% \mathrm{Cl}\end{array}$ \\
\hline Christian & $1.20 *(1.06-1.36)$ & $1.20 *(1.06-1.36)$ & $1.20^{*}(1.06-1.36)$ & $1.20 *(1.06-1.36)$ \\
\hline Others & $1.12(0.97-1.29)$ & 1.12(0.97-1.29) & $1.12(0.97-1.29)$ & 1.12(0.97-1.29) \\
\hline \multicolumn{5}{|l|}{ Caste } \\
\hline Scheduled Caste & Ref & Ref & Ref & Ref \\
\hline Scheduled Tribe & $0.67^{*}(0.59-0.77)$ & $0.67^{*}(0.59-0.77)$ & $0.67 *(0.59-0.77)$ & $0.67^{*}(0.59-0.77)$ \\
\hline Other Backward Class & $1.02(0.93-1.12)$ & $1.02(0.93-1.12)$ & $1.02(0.93-1.12)$ & $1.02(0.93-1.12)$ \\
\hline Others & $1.10^{*}(1.00-1.22)$ & $1.10^{*}(1.00-1.22)$ & $1.10(1.00-1.21)$ & $1.10^{*}(1.00-1.22)$ \\
\hline \multicolumn{5}{|l|}{ Place of residence } \\
\hline Rural & Ref & Ref & Ref & Ref \\
\hline Urban & $1.43^{*}(1.34-1.53)$ & $1.43^{*}(1.33-1.52)$ & $1.42^{*}(1.33-1.52)$ & $1.43 *(1.34-1.53)$ \\
\hline \multicolumn{5}{|l|}{ Region } \\
\hline North & Ref & Ref & Ref & Ref \\
\hline Central & $0.71 *(0.63-0.8)$ & $0.71 *(0.63-0.8)$ & $0.71 *(0.63-0.80)$ & $0.71 *(0.63-0.80)$ \\
\hline East & $1.21 *(1.09-1.33)$ & $1.21 *(1.09-1.34)$ & $1.21^{*}(1.09-1.34)$ & $1.21 *(1.09-1.33)$ \\
\hline Northeast & $0.72^{*}(0.63-0.83)$ & $0.72^{*}(0.63-0.83)$ & $0.72^{*}(0.63-0.83)$ & $0.72 *(0.63-0.83)$ \\
\hline West & $1.42^{*}(1.28-1.58)$ & $1.42^{*}(1.28-1.58)$ & $1.42^{*}(1.28-1.58)$ & $1.42 *(1.28-1.58)$ \\
\hline South & $1.88^{*}(1.71-2.07)$ & $1.88^{*}(1.71-2.07)$ & $1.88^{*}(1.71-2.07)$ & $1.88^{*}(1.71-2.07)$ \\
\hline \multicolumn{5}{|l|}{ Obese/overweight \# gender } \\
\hline Yes \# male & & Ref & & \\
\hline No \# male & & $0.66^{*}(0.59-0.73)$ & & \\
\hline No \# female & & $0.55^{*}(0.49-0.62)$ & & \\
\hline Yes \# female & & $0.93(0.82-1.06)$ & & \\
\hline \multicolumn{5}{|c|}{ High risk waist circumference \# gender } \\
\hline Yes \# male & & & Ref & \\
\hline No \# male & & & $0.72^{*}(0.62-0.82)$ & \\
\hline No \# female & & & $0.59^{*}(0.50-0.69)$ & \\
\hline Yes \# female & & & $1.03(0.90-1.20)$ & \\
\hline \multicolumn{5}{|c|}{ High risk waist-hip ratio \# gender } \\
\hline Yes \# male & & & & Ref \\
\hline No \# male & & & & $0.67^{*}(0.6-0.76)$ \\
\hline No \# female & & & & $0.60 *(0.53-0.69)$ \\
\hline Yes \# female & & & & $0.86^{*}(0.78-0.94)$ \\
\hline
\end{tabular}

Ref Reference; \#: Interaction; *if $p<0.05$; AOR Adjusted odds ratio, MPCE, Monthly per capita consumption expenditure

burden among higher socioeconomic groups [58]. This however can be attributed to the higher rate of surveillance bias in the diagnosis of chronic diseases among socioeconomically vulnerable populations [57]. It is also accompanied by their lack of information on the need for diagnosis and treatment of the diseases [14]. Again, as evidence suggests it is oftentimes difficult to obtain appropriate medical advices on different combinations of chronic diseases suffered by older individuals especially in poor socioeconomic settings [59]. Thus, health interventions should pay special attention on in detecting and treating multi-morbid older populations and frame disease-specific policies accordingly. Future studies with multiple disease combinations are also warranted for better understanding the morbidity pattern since clusters of diseases and their frequencies could inform treatment guidelines on how healthcare can be designed and delivered $[60,61]$. Research on the dynamic changes in these combinations by analysing longitudinal data (possibly with future waves of LASI survey) is also required to understand the ageing trajectories of multi-morbidity.

In agreement with a few cross-sectional as well as longitudinal studies, in the present study, late-life physical inactivity was associated with a higher likelihood of multi-morbidity [2, 62-64]. The finding supports the previous evidence suggesting that the changes in lifestyle and increased sedentary behaviour among older adults are associated with increased rates of multi-morbidity 
$[25,65]$. This is also an important finding with crucial impact in terms of preventive strategies that calls for special attention from health-decision makers in the country. Nevertheless, results on lifestyle factors such as smoking and alcohol consumption with no significant association with multi-morbidity are inconsistent with multiple studies that have shown tobacco use and alcohol drinking as major risk factors of higher prevalence of multiple chronic conditions [66-68]. Contrarily, some studies found that daily or weekly consumption of alcohol was inversely associated with multi-morbidity [69]. Thus, the current finding with no significance may be attributed to the dichotomous nature of the response which captures only ever use of tobacco and alcohol, suggesting the need for further investigation.

Furthermore, the interactive effect of gender in the associations of obesity-related measures and multi-morbidity shows that older men with overweight/obesity are at greater risk for multi-morbidity than their women counterparts. The male disadvantage in being multi-morbid observed in the current analyses can be attributed to the hormonal differences between males and females, genetic factors and differences in clinical severity [70].. Similarly, as documented, men may have a higher number of chronic conditions that are clinically more severe than among women, this may partially explain the higher prevalence of multi-morbidity among older men [70].

Finally, the regional variations and urban- rural gradient in the prevalence of multi-morbidity suggest that older adults from southern states of the country which are socioeconomically advantaged with relatively developed healthcare system and higher levels of education and income [58], and those from urban areas were at increased risk for being multi-morbid. This can be explained by the greater prevalence of several diseases in more urbanised areas and in wealthy people due to their lower engagements in physical activity and farming and unhealthy dietary habits [71, 72]. The finding can also be explained by the variations in healthcare facilities and differential accessibility which result in higher rate of disease diagnosis in urban and better-off regions of the country.

There were some limitations to be acknowledged in the present study. The cross-sectionality of the study makes it unfeasible to infer the causation in the observed directions of the relationships. Also, it uses a relatively simple definition of counting diseases for measuring multi-morbidity in variance with earlier studies [33, 73, 74]. The chronic conditions selected in our study of multi-morbidity did not include skin conditions, eye diseases, thyroid, urinary problems, liver diseases and gastrointestinal problems, thus, future investigation is required with a higher number of diseases. Previous studies also suggested that the prevalence of multi-morbidity varies according to data source and multiple data can provide better understanding of the disease prevalence [27]. Additionally, along with a few missing cases in the data that lead to possible selection bias, the self-reported chronic conditions in our study are subject to measurement error due to under-diagnosis. Again, with regard to the tobacco and alcohol consumption as factors of multimorbidity, the dose and duration and the consumption pattern were not considered in the study due to unavailability of data. Despite these limitations, there are major strengths too. The study utilizes the information of large nationally representative sample of the older population and obesity-related indicators that are measured. Hence, the findings of the current study are generalizable to the older adults in India and other aging populations in low and middle income countries.

\section{Conclusion}

The results of the study show significant gender differences in the prevalence of multi-morbidity between older men and women, men being at increased risk in the multivariate analysis which is uncommon in the existing epidemiological research. The findings highlight the need for better management of chronic conditions in older adults in primary care, increased prevention measures including nutritional interventions, physical activity promotion etc., information and physician education with a special focus on those who are obese, overweight or with highrisk waist circumference and waist-hip ratio. Interactive effect of male gender with anthropometric measures on multi-morbidity reported in our study probably due to increased unhealthy behaviours among men, requires further research. Also, studies are required on multimorbidity patterns and several combinations of morbidities and its impact stratified by gender among the aging population in India.

\section{Abbreviations}

AOR: Adjusted odds ratio; MPCE: Monthly per capita expenditure; Cl: Confidence interval; BMI: Body mass index; LASI: Longitudinal Aging Study in India; WC: Waist circumference; WHR: Waist hip ratio.

\section{Acknowledgements}

Not applicable

\section{Authors' Contribution}

The concept was drafted by TM and SS; SS contributed to the analysis design, SS advised on the paper and assisted in paper conceptualization. TM, SS, BB and MK contributed to the comprehensive writing of the article. All authors read and approved the final manuscript.

Author's information

T. Muhammad completed his M.Phil. in Population Studies and currently pursuing his Ph.D. in Population Studies at International Institute for Population Sciences, Mumbai, India. 
Bandita Boro has completed her M.Phil. in Population studies and is currently pursuing PhD in Population studies from Centre for the Study of Regional Development, JNU. Her area of interest is Ageing and Health, socio-economic determinants of health.

Manish Kumar completed his M.Phil. in Population Studies and currently pursuing his Ph.D. in Population Studies at International Institute for Population Sciences, Mumbai.

Shobhit Srivastava completed his M.Phil. in Population Studies and currently pursuing his Ph.D. in Population Studies at International Institute for Population Sciences, Mumbai.

\section{Funding}

Authors did not receive any funding to carry out this research.

\section{Availability of data and materials}

The study utilizes a secondary source of data that is freely available in public domain through request from https://iipsindia.ac.in/sites/default/files/LASI_ DataRequestForm_0.pdf

\section{Declarations}

\section{Ethics approval and consent to participate}

The data is freely available in the public domain and survey agencies that conducted the field survey for the data collection have collected prior consent from the respondent. The study was approved by the ethics committee or Institutional review board of The Indian Council of Medical Research (ICMR).

\section{Consent for publication}

Not applicable.

\section{Competing interests}

The authors declare that they have no competing interests.

\section{Author details}

${ }^{1}$ International Institute for Population Sciences, Mumbai, Maharashtra 400088 India. ${ }^{2}$ Centre for the Study of Regional Development (CSRD), School of Social Sciences-3 (SSS 3), Jawaharlal Nehru University (JNU), New Delhi 110067, India.

Received: 9 April 2021 Accepted: 24 February 2022

Published online: 01 March 2022

\section{References}

1. Collaborators GBD 2015 O. Health effects of overweight and obesity in 195 countries over 25 years. N Engl J Med. 2017;377:13-27.

2. $\mathrm{Ng} \mathrm{M}$, Fleming T, Robinson M, et al. Global, regional, and national prevalence of overweight and obesity in children and adults during 1980-2013: A systematic analysis for the Global Burden of Disease Study 2013. The Lancet. 2014;384:766-81.

3. Di Cesare M, Bentham J, Stevens GA, et al. Trends in adult body-mass index in 200 countries from 1975 to 2014: A pooled analysis of 1698 population-based measurement studies with 19.2 million participants. Lancet. 2016;387:1377-96.

4. WHO. Global Status Report on Non-Communicable Diseases 2010. Geneva, 2011.

5. WHO. Diet, Nutrition and the Prevention of Chronic Diseases: Report of a Joint WHO/FAO Expert Consultation. Geneva, 2003.

6. Fortin M, Lapointe L, Hudon C, et al. Multimorbidity and quality of life in primary care: a systematic review. Health Qual Life Outcomes. 2004:2:1-12.

7. Pati S, Swain S, Knottnerus JA, et al. Health related quality of life in multimorbidity: a primary-care based study from Odisha, India. Health Qual Life Outcomes. 2019:17:1-11.

8. Nguyen H, Manolova G, Daskalopoulou C, et al. Prevalence of multimorbidity in community settings: A systematic review and meta-analysis of observational studies. J comorbidity. 2019;9:2235042X19870934.

9. Bahat G, Tufan F, Bahat Z, et al. Comorbidities, polypharmacy, functionality and nutritional status in Turkish community-dwelling female elderly. Aging Clin Exp Res. 2014;26:255-9.
10. Bahat G, Tufan F, Bahat Z, et al. Assessments of functional status, comorbidities, polypharmacy, nutritional status and sarcopenia in Turkish community-dwelling male elderly. Aging Male. 2013;16:67-72.

11. Pati S, Swain S, Metsemakers J, et al. Pattern and severity of multimorbidity among patients attending primary care settings in Odisha. India PLoS One. 2017;12:e0183966.

12. Mini GK, Thankappan KR. 2017. Pattern, correlates and implications of non-communicable disease multimorbidity among older adults in selected Indian states: A cross-sectional study. BMJ Open. Epub ahead of print. https://doi.org/10.1136/bmjopen-2016-013529.

13. Banjare P, Pradhan J. 2014. Socio-economic inequalities in the prevalence of multi-morbidity among the rural elderly in Bargarh district of Odisha (India). PLoS One; 9. Epub ahead of print. https://doi.org/10. 1371/journal.pone.0097832.

14. Kunna R, San Sebastian M, Stewart WJ. Measurement and decomposition of socioeconomic inequality in single and multimorbidity in older adults in China and Ghana: Results from the WHO study on global AGEing and adult health (SAGE). International Journal for Equity in Health. 2017;16:1-17.

15. Booth HP, Prevost AT, Gulliford MC. Impact of body mass index on prevalence of multimorbidity in primary care: Cohort study. Fam Pract. 2014;31:38-43.

16. Dhalwani NN, Zaccardi F, O'Donovan G, et al. Association between lifestyle factors and the incidence of multimorbidity in an older english population. Journals of Gerontology - Series A Biological Sciences and Medical Sciences. 2017;72:528-34.

17. Bahat G, Tufan F, Saka B, et al. Which body mass index (BMI) is better in the elderly for functional status? Arch Gerontol Geriatr. 2012;54:78-81.

18. Ezzati M, Lopez AD, Rodgers AA, et al. Comparative quantification of health risks: global and regional burden of disease attributable to selected major risk factors. World Health Organization, 2004.

19. Kearns K, Dee A, Fitzgerald AP, et al. Chronic disease burden associated with overweight and obesity in Ireland: the effects of a small BMI reduction at population level. BMC Public Health. 2014;14:143.

20. Woo J, Ho SC, Yu ALM, et al. Is waist circumference a useful measure in predicting health outcomes in the elderly? Int J Obes. 2002;26:1349-55.

21. Nagel G, Peter R, Braig $S$, et al. The impact of education on risk factors and the occurrence of multimorbidity in the EPIC-Heidelberg cohort. BMC Public Health. 2008:8:384.

22. Zhang J, Xu L, Li J, et al. Association between obesity-related anthropometric indices and multimorbidity among older adults in Shandong, China: A cross-sectional study. BMJ Open. Epub ahead of print 2020. https://doi.org/10.1136/bmjopen-2019-036664.

23. Marengoni A, Angleman S, Melis R, et al. Aging with multimorbidity: A systematic review of the literature. Ageing Research Reviews. Epub ahead of print 2011. https://doi.org/10.1016/j.arr.2011.03.003.

24. Luhar S, Timæus IM, Jones R, et al. Forecasting the prevalence of overweight and obesity in India to 2040. PloS one. 2020;15:e0229438.

25. Srivastava S, Joseph KJV, Dristhi D, et al. Interaction of physical activity on the association of obesity-related measures with multimorbidity among older adults: a population-based cross-sectional study in India. BMJ Open. 2021;11:e050245.

26. International Institute for Population Sciences (IIPS), NPHCE, MoHFW, et al. Longitudinal Ageing Study in India (LASI) Wave 1. Mumbai, India, 2020.

27 Gontijo Guerra S, Berbiche D, Vasiliadis H-M. Measuring multimorbidity in older adults: comparing different data sources. BMC Geriatrics. 2019;19:1-11.

28. Nicholson K, Almirall J, Fortin M. The measurement of multimorbidity. Health Psychol. 2019;38:783-90.

29. Fortin M, Stewart M, Poitras ME, et al. A systematic review of prevalence studies on multimorbidity: Toward a more uniform methodology. Ann Fam Med. 2012;10:142-51.

30. Fortin M, Almirall J, Nicholson K. Development of a research tool to document self-reported chronic conditions in primary care. Journal of Comorbidity. 2017;7:117.

31. Pati S, Swain S, Hussain MA, et al. Prevalence and outcomes of multimorbidity in South Asia: A systematic review. BMJ Open; 5. Epub ahead of print 2015. https://doi.org/10.1136/bmjopen-2014-007235. 
32. Jovic D, Marinkovic J, Vukovic D. Association between body mass index and prevalence of multimorbidity: a cross-sectional study. Public Health. 2016:139:103-11.

33 Kirchberger I, Meisinger C, Heier M, et al. Patterns of multimorbidity in the aged population results from the KORA-Age study. PLoS One. 2012;7:1-7.

34. Wei MY, Levine DA, Zahodne LB, et al. Multimorbidity and Cognitive Decline Over 14 Years in Older Americans. J Gerontol A Biol Sci Med Sci. 2020;75:1206-13.

35. Agborsangaya CB, Ngwakongnwi E, Lahtinen $M$, et al. Multimorbidity prevalence in the general population: The role of obesity in chronic disease clustering. BMC Public Health; 13. Epub ahead of print 2013. https:// doi.org/10.1186/1471-2458-13-1161.

36. McKenna SP. Measuring patient-reported outcomes: Moving beyond misplaced common sense to hard science. BMC Medicine. Epub ahead of print 2011. https://doi.org/10.1186/1741-7015-9-86.

37. Zhang J, Xu L, Li J, et al. Association between obesity-related anthropometric indices and multimorbidity among older adults in Shandong, China: A cross-sectional study. BMJ Open. 2020;10:1-8.

38. Muhammad T, Govindu M, Srivastava S. Relationship between chewing tobacco, smoking, consuming alcohol and cognitive impairment among older adults in India: a cross-sectional study. BMC Geriatr. 2021;21:85.

39. Srivastava S, Kumar S. Does socio-economic inequality exist in micronutrients supplementation among children aged 6 - 59 months in India ? Evidence from National Family Health. 2021; 21(1)::1-12.

40. Fan C, Wang L, Wei L. Comparing Two Tests for Two Rates. American Statistician. Epub ahead of print 2017. https://doi.org/10.1080/00031305. 2016.1246263.

41. Osborne J, King JE. Binary Logistic Regression. In: Best Practices in Quantitative Methods. SAGE Publications, Inc., 2011, pp. 358-384.

42. Lewis-Beck M, Bryman A, Liao TF. Variance Inflation Factors. In: The SAGE Encyclopedia of Social Science Research Methods. 2004, pp. 1175-1176.

43. Chauhan S, Srivastava S, Kumar P, et al. Interaction of substance use with physical activity and its effect on depressive symptoms among adolescents. Journal of Substance Use 2020;26(5)::1-7.

44. Van Der Weele TJ, Knol MJ. A tutorial on interaction. Epidemiologic. Methods. 2014:3:33-72.

45. Schäfer I, von Leitner EC, Schön G, et al. Multimorbidity patterns in the elderly: A new approach of disease clustering identifies complex interrelations between chronic conditions. PLOS ONE; 5. Epub ahead of print 2010. https://doi.org/10.1371/journal.pone.0015941.

46. Abad-Díez JM, Calderón-Larrañaga A, Poncel-Falcó A, et al. Age and gender differences in the prevalence and patterns of multimorbidity in the older population. BMC Geriatr. 2014;14:75.

47. Jawed M, Inam S, Shah N, et al. Association of obesity measures and multimorbidity in Pakistan: findings from the IMPACT study. Public Health. 2020;180:51-6.

48. Hussin NM, Shahar S, Din NC, et al. Incidence and predictors of multimorbidity among a multiethnic population in Malaysia: a community-based longitudinal study. Aging Clin Exp Res. 2019;31:215-24.

49. Romano E, Ma R, Vancampfort D, et al. Multimorbidity and obesity in older adults from six low- and middle-income countries. Preventive Medicine. 2021;153:106816.

50. Bramhankar M, Pandey M, Rana GS, et al. An assessment of anthropometric indices and its association with NCDs among the older adults of India: evidence from LASI Wave-1. BMC Public Health. 2021:21:1-13.

51. Singh K, Patel SA, Biswas S, et al. Multimorbidity in South Asian adults: Prevalence, risk factors and mortality. Journal of Public Health (United Kingdom). 2019;41:80-9.

52. Marengoni A, Angleman S, Melis R, et al. Aging with multimorbidity : A systematic review of the literature. Ageing Res Rev. 2011;10:430-9.

53. Violan C, Foguet-Boreu Q, Flores-Mateo G, et al. Prevalence, determinants and patterns of multimorbidity in primary care: A systematic review of observational studies. PLOS ONE. 2014;9:3-11.

54 Kriegsman DMW, Penninx BWJH, Van Eijk JTM, et al. Self-reports and general practitioner information on the presence of chronic diseases in community dwelling elderly. A study on the accuracy of patients'self-reports and on determinants of inaccuracy. J Clin Epidemiol. 1996;49:1407-17.

55. Boutayeb A, Boutayeb S. The burden of non communicable diseases in developing countries. International Journal for Equity in Health. 2005:4:1-8
56. Pati S, Hussain MA, Swain S, et al. Development and Validation of a Questionnaire to Assess Multimorbidity in Primary Care: An Indian Experience. BioMed Research International; 2016. Epub ahead of print 2016. https:// doi.org/10.1155/2016/6582487

57. Basu S, King AC. Disability and chronic disease among older adults in India: Detecting vulnerable populations through the WHO SAGE Study. Am J Epidemiol. 2013;178:1620-8.

58. Arokiasamy P, Uttamacharya, Jain K. Multi-morbidity, functional limitations, and self-rated health among older adults in India: Cross-sectional analysis of LASI pilot survey, 2010. SAGE Open; 5. Epub ahead of print 2015. https://doi.org/10.1177/2158244015571640.

59. Alaba O, Chola L. The social determinants of multimorbidity in South Africa. International Journal for Equity in Health. 2013;12:1-10.

60. Chang AY, Gómez-Olivé FX, Payne C, et al. Chronic multimorbidity among older adults in rural South Africa. BMJ Global Health; 4. Epub ahead of print 2019. https://doi.org/10.1136/bmjgh-2018-001386.

61. Hussain MA, Huxley RR, Al MA. Multimorbidity prevalence and pattern in Indonesian adults: An exploratory study using national survey data. BMJ Open. 2015;5:1-10.

62. Vancampfort D, Smith L, Stubbs B, et al. Associations between active travel and physical multi-morbidity in six low- and middle-income countries among community-dwelling older adults: A cross-sectional study. PLoS ONE. Epub ahead of print 2018. https://doi.org/10.1371/journ al.pone.0203277.

63. Steeves JA, Shiroma EJ, Conger SA, et al. Physical activity patterns and multimorbidity burden of older adults with different levels of functional status: NHANES 2003-2006. Disabil Health J. 2019;12:495-502.

64. Li X, Cai L, Cui WL, et al. Association of socioeconomic and lifestyle factors with chronic non-communicable diseases and multimorbidity among the elderly in rural southwest China. Journal of Public Health (United Kingdom). 2020;42:1-8.

65. Autenrieth CS, Kirchberger I, Heier M, et al. Physical activity is inversely associated with multimorbidity in elderly men: Results from the KORAAge Augsburg Study. Prev Med. 2013;57:17-9.

66. Stewart D, Mccambridge J. Alcohol complicates multimorbidity in older adults. The BMJ. 2019;365:2-3

67. Kivimäki M, Kuosma E, Ferrie JE, et al. Overweight, obesity, and risk of cardiometabolic multimorbidity: pooled analysis of individual-level data for 120813 adults from 16 cohort studies from the USA and Europe. The Lancet Public Health. 2017;2:e277-85.

68. Blumental-Perry A. Unfolded Protein Response in Chronic Obstructive Pulmonary Disease: Smoking, Aging and Disease: A SAD Trifecta. Curr Mol Med. 2012;12:883-98.

69. Sakib MN, Shooshtari S, St John P, et al. The prevalence of multimorbidity and associations with lifestyle factors among middle-aged Canadians: An analysis of Canadian Longitudinal Study on Aging data. BMC Public Health. 2019;19:1-13.

70. Mauvais-Jarvis F, Bairey Merz N, Barnes PJ, et al. Sex and gender: modifiers of health, disease, and medicine. The Lancet. 2020;396:565-82.

71. Van de Poel E, O'Donnell O, Van Doorslaer E. Urbanization and the spread of diseases of affluence in China. Econ Hum Biol. 2009:7:200-16.

72. Garin N, Koyanagi A, Chatterji S, et al. Global Multimorbidity Patterns: A Cross-Sectional, Population-Based, Multi-Country Study. Journals of Gerontology - Series A Biological Sciences and Medical Sciences. 2016;71:205-14.

73. Hudon C, Fortin M, Vanasse A. Cumulative Illness Rating Scale was a reliable and valid index in a family practice context. J Clin Epidemiol. 2005:58:603-8

74. Valderas JM, Starfi B, Sibbald B. Defining Comorbidity: Implications for Understanding Health and Health Services. Ann Fam Med. 2009;7(4):357-63.

\section{Publisher's Note}

Springer Nature remains neutral with regard to jurisdictional claims in published maps and institutional affiliations. 